\title{
Childhood dietary trajectories and adolescent cardiovascular phenotypes: Australian community-based longitudinal study
}

\author{
Jessica A Kerr ${ }^{1,2, *}$, Alanna N Gillespie ${ }^{1,2}$, Constantine E Gasser ${ }^{1,2}$, Fiona K Mensah ${ }^{1,2}$, \\ David Burgner ${ }^{1,2,3}$ and Melissa Wake ${ }^{1,2,4}$ \\ 'Centre for Community Child Health, Murdoch Children's Research Institute, The Royal Children's Hospital, \\ Flemington Road, Parkville, VIC 3052, Australia: ${ }^{2}$ Department of Paediatrics, The University of Melbourne, Parkville, \\ VIC, Australia: ${ }^{3}$ Department of Paediatrics, Monash University, Clayton, VIC, Australia: ${ }^{4}$ Department of Paediatrics \& \\ the Liggins Institute, University of Auckland, Auckland, New Zealand
}

Submitted 13 September 2017: Final revision received 12 April 2018: Accepted 24 April 2018: First published online 27 June 2018

\begin{abstract}
Objective: With the intention to inform future public health initiatives, we aimed to determine the extent to which typical childhood dietary trajectories predict adolescent cardiovascular phenotypes.

Design: Longitudinal study. Exposure was determined by a $4 \mathrm{~d}$ food diary repeated over eight waves (ages 4-15 years), coded by Australian Dietary Guidelines and summed into a continuous diet score (0-14). Outcomes were adolescent (Wave 8, age 15 years) blood pressure, resting heart rate, pulse wave velocity, carotid intimamedia thickness, retinal arteriole-to-venule ratio. Latent class analysis identified 'typical' dietary trajectories from childhood to adolescence. Adjusted linear regression models assessed relationships between trajectories and cardiovascular outcomes, adjusted for a priori potential confounders.

Setting: Community sample, Melbourne, Australia.

Subjects: Children ( $n$ 188) followed from age 4 to 15 years.

Results: Four dietary trajectories were identified: unhealthy (8\%); moderately unhealthy (25\%); moderately healthy (46\%); healthy (21\%). There was little evidence that vascular phenotypes associated with the trajectories. However, resting heart rate (beats/min) increased $(\beta ; 95 \% \mathrm{CI})$ across the healthy (reference), moderately healthy $(4 \cdot 1 ;-0 \cdot 6,8 \cdot 9 ; P=0 \cdot 08)$, moderately unhealthy $(4 \cdot 5 ;-0 \cdot 7,9 \cdot 7$; $P=0.09)$ and unhealthy $(10 \cdot 5 ; 2 \cdot 9,18 \cdot 0 ; P=0 \cdot 01)$ trajectories.

Conclusions: Decade-long dietary trajectories did not appear to influence macroor microvascular structure or stiffness by mid-adolescence, but were associated with resting heart rate, suggesting an early-life window for prevention. Larger studies are needed to confirm these findings, the threshold of diet quality associated with these physiological changes and whether functional changes in heart rate are followed by phenotypic change.
\end{abstract}

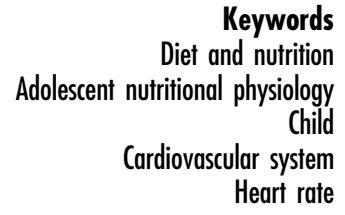

Keywords yiology Heart rate
Atherosclerosis, the infiltration of inflammatory cells and lipid into arterial walls, begins in childhood and causes later $\mathrm{CVD}^{(1)}$. The most prevalent risk factors for CVD are modifiable ${ }^{(2)}$. Because unhealthy diets cause inflammation to blood vessels and internal organs ${ }^{(3)}$, there is a strong link between diet quality and cardiovascular health in adults $^{(4)}$. It is estimated that following dietary guidelines throughout adulthood could reduce the population-level burden of CVD by at least $20 \%{ }^{(5)}$.

Although dietary intervention in adulthood can mitigate CVD risk ${ }^{(6)}$, greater benefits might be obtained if healthy diets were initiated and sustained from childhood ${ }^{(7-9)}$. Unfortunately, many children do not consume the healthy diets $^{(10,11)}$ shown to reduce CVD in adults ${ }^{(6)}$. Therefore, various intervention studies have been established among children. The Special Turku Coronary Risk Factor Intervention Project (STRIP) randomised more than 1000 infants to an unrestricted diet (control) or to repeated dietary counselling facilitating a diet continually low in saturated fats and cholesterol ${ }^{(12)}$. Throughout late childhood and adolescence, those in the intervention group had healthier body weight, blood pressure, total cholesterol and LDLcholesterol $^{(13-16)}$. By adolescence, those in the intervention group had better American Heart Association cardiovascular health scores, which were associated with less adverse cardiovascular intermediate phenotypes, namely 
reduced aortic intima-media thickness and increased aortic elasticity ${ }^{(13)}$.

While randomised trials are paramount, continued observational research into children's routine diet and cardiovascular phenotypes is still needed ${ }^{(17)}$ to pinpoint the level of childhood dietary quality necessary to trigger cardiovascular change and to better understand the best window during childhood for optimal intervention. Observational studies have shown robust associations of childhood and adolescent consumption of foods and beverages high in sugar/fat or low in protein/fibre with poor CVD risk scores, blood pressure, TAG and total cholesterol levels or retinal microcirculatory health ${ }^{(18-26)}$. Similarly, increasing consumption of sugary beverages or decreasing consumption of dairy, fruit or vegetables throughout adolescence has been associated with increased cardiometabolic risk factors in late adolescence ${ }^{(27-29)}$.

However, because foods are not consumed in isolation, it is more meaningful to study children's whole diet, rather than studying links between individual foods and CVD risk. Questionnaire-derived dietary scores are often based on dietary guidelines or other a priori principles and broadly capture 'whole' diet quality. Some dietary quality scores predict CVD events in adults and improve the accuracy of CVD risk prediction models ${ }^{(30,31)}$. However, this approach has not been widely applied to children ${ }^{(32)}$. Nevertheless, a handful of cross-sectional studies do demonstrate that superior diet scores inversely associate with childhood/adolescent blood pressure, augmentation index or composite CVD risk score ${ }^{(33-35)}$. Only one group has investigated the association between a score based on the Australian Dietary Guidelines and cardiometabolic risk factors among children or adolescents; worsening diet scores (between 14 and 17 years of age) were associated with increasing heart rate, TAG, insulin and insulin resistance levels ${ }^{(36)}$.

The method of trajectory analyses, which identifies groups of participants whose dietary scores closely correspond with one another over time, is emerging in this field ${ }^{(37,38)}$. This novel approach to capture children's dietary change is uncommon because few studies have the required measures of diet repeated over a sustained period of childhood. However, public health researchers recognise the value in tracking multiple dietary scores/ patterns within childhood ${ }^{(39-43)}$ and using these data to predict later outcomes ${ }^{(7,44-47)}$. From a public health perspective, longitudinal trajectory analysis of childhood diet would help to improve understanding of population-level health outcomes ${ }^{(48)}$, including adolescent cardiovascular health.

The physiological development of cardiovascular damage begins in childhood ${ }^{(1)}$. However, no studies have yet investigated dietary trajectories across multiple time points from pre-school to adolescence and their association with a comprehensive battery of measured cardiovascular phenotypes in this age group. This could provide insights into typical life-course dietary pathways to lifelong cardiovascular health. For example, it might be that two children follow the same unhealthy trajectory throughout early and middle childhood, but that one becomes much healthier during adolescence. It is of public health interest to understand if this child has better heart health or whether perhaps the healthy change has occurred too late. This could clarify when to target dietary intervention most effectively for better cardiovascular health. In contrast, important and clinically valuable information would be lost by relying on children's average dietary habits over a decade.

In a community-based longitudinal study between 2002 and 2014, we repeatedly measured children's diet at eight time points using the same $4 \mathrm{~d}$ food diary, and then empirically derived dietary trajectories. In 2014, when participants were adolescent, we measured their intermediate cardiovascular risk phenotypes. Specifically, in the present exploratory study of 188 adolescents we aimed to:

1. empirically derive typical dietary trajectories from age 4 to 15 years; and

2. explore which, if any, trajectories predict better vascular phenotypes at age 15 years.

\section{Methods}

\section{Participants and procedures}

The Parent Education and Support (PEAS) study is a prospective community-based birth cohort study conducted in Melbourne, Australia (population 3.3 million at time of initial recruitment). Recruitment and follow-up are detailed elsewhere ${ }^{(49-51)}$. From thirty-one local government areas, three areas were selected for recruitment to provide a broad range of sociodemographic characteristics. Families were recruited from one low, one medium and one highly advantaged local government area (mean annual birth rate per local government area $=1350$ ). Maternal and Child Health Nurses, who provide universal care to all Melbourne children aged $0-5$ years, invited parents of all firstborn newborns within the three recruitment areas to participate in PEAS. This initial recruitment took place between June 1998 and February 2000. PEAS originally aimed to test the efficacy of brief evidence-based support for common parenting issues during the child's first two years ${ }^{(50)}$. However, because child health outcomes were similar between control and intervention arms, groups were combined into a single cohort.

The renamed PEAS Kids Growth Study followed these children from age 4 years. It collected data on children's growth and development every 6 months (see Fig. 1, adapted from Hanvey et al. ${ }^{(51)}$ ) from age 4 (current study Wave $1, n 402$ ) to 6.5 years (current study Wave $6, n 317$ ), then again at age 10 (current study Wave $7, n$ 261) and 15 years (current study Wave $8, n$ 203). All waves included anthropometric measurement and questionnaires, which 


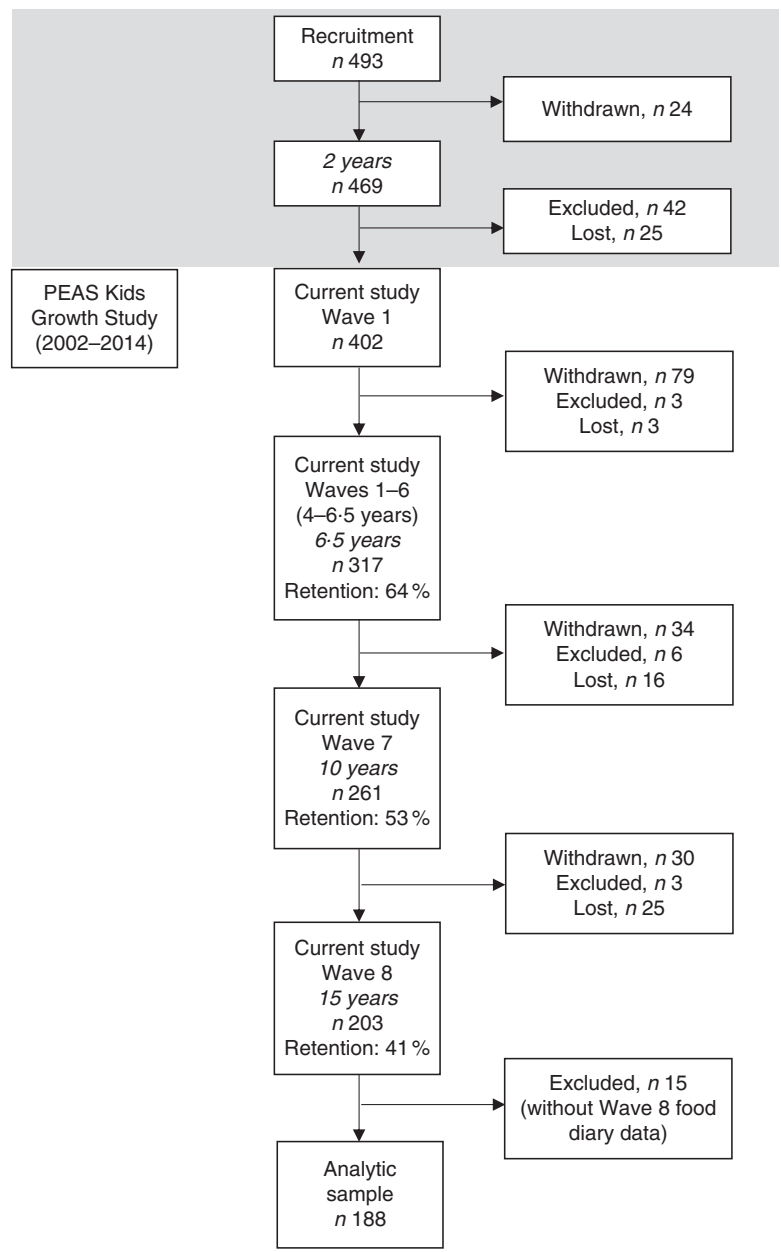

Fig. 1 Participant retention in the Parent Education and Support (PEAS) Kids Growth study. The grey shading refers to the original PEAS Study (in which recruitment took place) before it was renamed the PEAS Kids Growth Study

included the $4 \mathrm{~d}$ food diary. At Wave 8, researchers collected height, weight and cardiovascular assessments at Melbourne's Royal Children's Hospital or at home between February and October 2014. Parents and adolescents provided written informed consent. The Royal Children's Hospital Ethics Committee approved all protocols (approval number 28153).

\section{Measures}

Food diary (Waves 1-8, age 4-15 years)

In Waves 1-6 parents completed the food diaries for their children, at Wave 7 children had the option to complete the food diary themselves, and at Wave 8 children completed the diary by themselves. Because children's dietary habits differ between weekend and weekdays ${ }^{(52)}$, the $4 \mathrm{~d}$ food diary asked participants to record their consumption (not eaten $=0$, eaten once $=1$, eaten twice or more $=2$ ) of twelve common food items (e.g. fruit, milk, water, confectionery) on two weekdays and two weekend days. If a participant missed a whole diary day, data were imputed from the completed weekend or weekday. Based upon a previously published score ${ }^{(37)}$, for each individual day we grouped the twelve items into seven common Australian food groups (fruit, vegetables, water, fatty foods, sugary foods, milk/milk products, sweetened drinks) which capture the majority of components relevant to emerging CVD (e.g. saturated fat, sugar, salt, fibre) ${ }^{(6)}$. We used the 2013 Australian Dietary Guidelines ${ }^{(53)}$ to assign each category a score of 0,1 or 2 . A score of 0 was assigned if participants did not meet the particular dietary guideline, 1 was assigned if the guideline was partially met and a score of 2 was given if the guideline was met. Fruit, vegetables, water and milk products or alternatives were positively coded and fatty foods, sugary foods and sweetened drinks were reverse/negatively coded. Participants' resulting 0-2 scores for each of the seven categories were summed to form a 0 14 score, with 14 indicating the highest possible dietary quality. Therefore, participants had four (two weekday, two weekend) 0-14-point diet scores that were then averaged to generate one weekday and one weekend score. To produce an overall diet quality score representative of participants' typical weeks, we multiplied this average weekday habit score by 5 and average weekend habit score by 2 , then computed the average score (0-14).

Vascular measures (Wave 8, age 15 years)

We collected data on pulse wave velocity, blood pressure, resting heart rate, carotid intima-media thickness and retinal arteriole-to-venule ratio. Collectively, these measures indicate the function and structure of the cardiovascular system and are associated with emerging cardiovascular health ${ }^{(54-58)}$.

Vascular function. Resting blood pressure was measured supine after a 2 min rest using the pulse wave analysis' setting of the SphygmoCor XCEL (AtCor Medical, NSW, Australia) ${ }^{(59)}$. A brachial cuff was fitted around the upper right arm. Medians of three measures (with intervals of 1 min between) were calculated for resting heart rate (beats/min, bpm) and brachial systolic and diastolic blood pressure $(\mathrm{mmHg})$.

Carotid-femoral pulse wave velocity, an indicator of arterial stiffness, was measured to the nearest $0.1 \mathrm{~m} / \mathrm{s}$ using a thigh cuff and tonometer. Trained research assistants measured the distance from participants' carotid pulse to sternal notch, femoral pulse to top of the thigh cuff and sternal notch to top of the thigh cuff. Pulse transit distance in metres was calculated by subtracting the first and second measure from the third measure. Assistants then used a tonometer to record the waveform of participants' carotid pulse, while femoral waveform was recorded by the inflated thigh cuff. Once ten pulse waves were recorded, pulse transit time in seconds was determined. Pulse wave velocity was calculated as 
distance (m)/time (s). Higher pulse wave velocity values indicate stiffer arteries (i.e. worse vascular function).

Vascular structure. Vascular structural measures were captured only in participants who could attend the centre-based visit ( $n$ 103), as portability limitations meant that equipment was not compatible with home visits. For carotid intima-media thickness, we acquired ultrasound images of the carotid artery (Vivid $i$; General Electronics Healthcare, USA) at end diastole with ECG gating, using a linear probe with a frequency of at least $8 \mathrm{MHz}$. Images of the right carotid artery were optimised to visualise the intima-media complex of the anterior and posterior walls of the right common carotid artery $1 \mathrm{~cm}$ proximal to the carotid bulb. Cine loops of at least five cardiac cycles were recorded and saved for later analysis by Heart Research at Murdoch Children's Research Institute using semi-automated edge-detection software (Carotid Analyzer $^{\mathrm{TM}}$ ). Increased carotid intima-media thickness indicates a thicker intima-media, an indicator of preclinical atherosclerosis.

Digital retinal photography was conducted with a nonmydriatic retinal camera CR-DGi with an EDS 300 SLR camera back using DH client software. We took photos of the right and left eye macula and retina. Saved images of the right eye retina were analysed for vessel calibres. Central retinal arteriole equivalent and central retinal venule equivalent were calculated using the 'big 6' methodology ${ }^{(23)}$. We calculated retinal arteriole-tovenule ratio by dividing the central retinal arteriole equivalent by the central retinal venule equivalent (converted to \%). A lower retinal arteriole-to-venule ratio indicates increased venule calibre, decreased arteriole calibre, or both increased venule and decreased arteriole calibres combined. These microvascular parameters have been associated with increased cardiovascular risk in adults $^{(60)}$

Table 1 Description of measures used in the PEAS Kids Growth Study, Melbourne, Australia, 2002-2014

\begin{tabular}{|c|c|c|c|}
\hline Construct & Measure & Wave & Additional information \\
\hline Maternal education & Maternal self-reported & 1 & $\begin{array}{l}\text { Mothers completed a questionnaire which asked about their } \\
\text { highest level of completed education: did not complete Year 12, } \\
\text { completed Year 12, degree educated. In Australia, Year } 12 \text { is } \\
\text { the final year of high school }\end{array}$ \\
\hline Neighbourhood-level SEP & SEIFA index & 1 & $\begin{array}{l}\text { Residential postcode was converted into SEIFA-IRSD score } \\
\text { (national mean } 1000 \text { (SD 100)) from the previous Australian } \\
\text { Bureau of Statistics } 5 \text {-yearly census }{ }^{(61)} \text {. A lower score indicates } \\
\text { more disadvantage }\end{array}$ \\
\hline Adolescent pubertal status & Self-reported & 8 & $\begin{array}{l}\text { As part of the questionnaire, participants completed the Pubertal } \\
\text { Development Scale }{ }^{(62)} \text {. Questions were dependent on } \\
\text { participants' sex and included items such as 'Would you say } \\
\text { that your growth in height (growth spurt) has: not started, barely } \\
\text { started, definitely started, seems complete?' Responses were } \\
\text { categorised into: pre-, early, mid-, late or postpubertal }\end{array}$ \\
\hline Adolescent physical activity & Accelerometry & 8 & $\begin{array}{l}\text { Accelerometers (model GT3X; ActiGraph LLC, Pensacola, FL, } \\
\text { USA) were used to objectively measure physical activity. The } \\
\text { participant was fitted with a waist-worn, lightweight } \\
\text { accelerometer during his/her appointment (Day } 0 \text { ) and asked to } \\
\text { wear it continuously for seven days. Non-wear times were } \\
\text { recorded on an accompanying activity log card. Movement was } \\
\text { recorded in } 60 \text { s epochs. Once accelerometers were returned } \\
\text { via post, data were downloaded using the accompanying } \\
\text { ActiLife program (version } 6 \text { ). Data from Day } 0 \text { and any day after } \\
\text { the seven-day wear period were discarded. The minimum data } \\
\text { required for inclusion were } \geq 4 \text { 'valid' days of } \geq 10 \mathrm{~h} \text { of non- } \\
\text { missing data between } 06.00 \text { and } 23.00 \text { hours. Missing data } \\
\text { were defined as any periods of } \geq 60 \text { min of consecutive ' } 0 \text { ' } \\
\text { counts. Average percentage time spent in moderate-to- } \\
\text { vigorous physical activity }(>2296 \text { counts/min) was defined } \\
\text { using Evenson's thresholds }\end{array}$ \\
\hline Adolescent BMI Z-score & $\begin{array}{l}\text { Researcher measured } \\
\text { participant's height } \\
\text { and weight }\end{array}$ & 8 & $\begin{array}{l}\text { Anthropometry-trained research assistants measured height } \\
\text { (portable rigid stadiometer model IP0955; Invicta, Leicester, } \\
\text { UK) as the mean of two measurements, or the median of three } \\
\text { measurements if the first two differed by }>0.5 \mathrm{~cm} \text {. They } \\
\text { measured weight with a calibrated digital scale (TI-THD646; } \\
\text { Tanita, Tokyo, Japan) with the participant wearing light clothing, } \\
\text { without shoes or socks. BMI was calculated as [weight (kg)]/ } \\
\text { [height (m)] } \text { [ }^{2} \text {. We used CDC reference values to calculate } \\
\text { adolescents' BMI Z-score }{ }^{(64)} \text {, using the Stata 'zanthro' } \\
\text { function }{ }^{(65)}\end{array}$ \\
\hline
\end{tabular}

PEAS, Parent Education and Support; SEP, socio-economic position; SEIFA, Socio-Economic Indexes for Areas; IRSD, Index of Relative Socio-economic Disadvantage; CDC, US Centers for Disease Control and Prevention. 


\section{Other measures}

At Waves 1 and 8, we also measured maternal education and socio-economic position, and children's age, sex, pubertal development, time spent in moderate-to-vigorous physical activity, height and weight (Table 1$)^{(61-65)}$.

\section{Analysis}

We required that participants had Wave 8 (age 15 years) food diary data to be included in trajectory analyses ( $n$ 188). On average, these participants had complete diary data for seven of the eight waves. For study aim 1, we conducted latent class analyses using Mplus $5.1^{(66)}$. This analysis identifies and allocates participants to their most likely dietary trajectory based on the similarity between participants' food diary measurements over time. We ascertained trajectory categories using up to eight of the participants' diet scores from age 4 to 15 years (i.e. Waves 1-8). We fitted models with two, three, four and five trajectories to the data, then selected the best model as judged from class size and model fit statistics. That is, $a$ priori we intended to select the model that had an entropy value greater than 0.8 and at least $5 \%$ of the sample in each class/trajectory, balanced with the lowest possible Bayesian information criterion (BIC), Akaike information criterion (AIC) and adjusted BIC values ${ }^{(67,68)}$. In addition, model fit was evaluated with $P$ values obtained from Vuong-Lo-Mendell-Rubin likelihood ratio tests of whether adding an additional trajectory category improved model fit ${ }^{(66)}$.

For analyses pertaining to study aim 2, we used these dietary trajectories as a categorical predictor in adjusted linear regression analyses (using Stata/IC 14.1). To be included in this analytic sample, we required participants to have completed a cardiovascular assessment at Wave 8 ( $n$ 188). Because of their potential gradient with both the exposure and outcomes ${ }^{(8,69-71)}$, a priori identified confounders were Wave 1 maternal education and socio-economic position, and Wave 8 child age, sex, pubertal development and percentage of time spent in moderate-to-vigorous physical activity. In our final model, we further adjusted for Wave 8 BMI $Z$-score, to determine the strength of association between the dietary trajectories and adolescent cardiovascular phenotypes regardless of adolescent body mass.

Table 2 Sample characteristics of the children from the PEAS Kids Growth Study, Melbourne, Australia, 2002-2014*

\begin{tabular}{|c|c|c|c|c|c|}
\hline & \multirow[b]{2}{*}{$n$} & \multicolumn{3}{|c|}{ Total (n 188) } & \multirow[b]{2}{*}{ Range } \\
\hline & & Mean & $\%$ & $\mathrm{SD}$ & \\
\hline \multicolumn{6}{|l|}{ Sociodemographic characteristics at outcome } \\
\hline Age (years) & 188 & $15 \cdot 1$ & & 0.5 & $14 \cdot 2-16 \cdot 2$ \\
\hline Male (\%) & 188 & & 48 & & - \\
\hline BMI Z-score & 187 & 0.4 & & 0.9 & $-2 \cdot 3-2 \cdot 5$ \\
\hline Puberty stage (\%) & 181 & & & & \\
\hline Prepubertal & 0 & - & & - & - \\
\hline Early pubertal & 8 & & 4 & & - \\
\hline Mid-pubertal & 29 & & 16 & & - \\
\hline Late pubertal & 119 & & 66 & & - \\
\hline Postpubertal & 25 & & 14 & & - \\
\hline Neighbourhood-level SEP & 187 & 1051 & & 41 & $882-1151$ \\
\hline Maternal education (\%) & 184 & & & & \\
\hline Did not complete high school & 37 & & 20 & & - \\
\hline Completed high school & 61 & & 33 & & - \\
\hline Completed tertiary or postgraduate study & 86 & & 47 & & - \\
\hline \multicolumn{6}{|l|}{ Exposure } \\
\hline \multicolumn{6}{|l|}{ Diet quality score } \\
\hline Wave 1 (age 4 years) & 163 & $10 \cdot 2$ & & $1 \cdot 8$ & $4 \cdot 9-14 \cdot 0$ \\
\hline Wave 2 (age 4.5 years) & 152 & $10 \cdot 4$ & & $1 \cdot 7$ & $4.9-13.4$ \\
\hline Wave 3 (age 5 years) & 137 & $10 \cdot 4$ & & $1 \cdot 7$ & $4.4-14 \cdot 0$ \\
\hline Wave 4 (age 5.5 years) & 160 & $10 \cdot 3$ & & $1 \cdot 6$ & $3.4-13 \cdot 0$ \\
\hline Wave 5 (age 6 years) & 167 & $10 \cdot 3$ & & $1 \cdot 6$ & $5 \cdot 0-13 \cdot 4$ \\
\hline Wave 6 (age 6.5 years) & 174 & $10 \cdot 2$ & & 1.6 & $5 \cdot 3-13 \cdot 3$ \\
\hline Wave 7 (age 10 years) & 149 & $10 \cdot 1$ & & $1 \cdot 6$ & $5 \cdot 0-13.6$ \\
\hline Wave 8 (age 15 years) & 188 & $9 \cdot 9$ & & $1 \cdot 7$ & $3 \cdot 7-13 \cdot 2$ \\
\hline \multicolumn{6}{|l|}{ Outcomes } \\
\hline Resting heart rate (bpm) & 186 & $66 \cdot 9$ & & $9 \cdot 9$ & $42 \cdot 0-94 \cdot 0$ \\
\hline Systolic blood pressure (mmHg) & 186 & $119 \cdot 3$ & & $9 \cdot 7$ & $91 \cdot 0-145 \cdot 0$ \\
\hline Diastolic blood pressure $(\mathrm{mmHg})$ & 186 & 65.9 & & $6 \cdot 2$ & $51 \cdot 0-85 \cdot 0$ \\
\hline Pulse wave velocity $(\mathrm{m} / \mathrm{s})$ & 177 & 4.6 & & 0.7 & $2.7-9.3$ \\
\hline Carotid intima-media thickness $(\mu \mathrm{m})$ & 99 & $475 \cdot 3$ & & $57 \cdot 3$ & $340 \cdot 0-570 \cdot 0$ \\
\hline Retinal arteriole-to-venule ratio (\%) & 103 & 69.1 & & $4 \cdot 8$ & $57 \cdot 0-82 \cdot 0$ \\
\hline
\end{tabular}

PEAS, Parent Education and Support; SEP, socio-economic position; bpm, beats/min.

${ }^{*}$ Data presented are mean and SD except for variables male, puberty stage and maternal education, which are \%. 


\section{Results}

Sample characteristics are shown in Table 2. On average, children were aged $4 \cdot 2$ (SD 0.2) years at Wave 1 and $15 \cdot 1$ (SD 0.5 ) years at Wave 8 . The sample contained a similar distribution of male and female participants, and the majority were classed as late pubertal at Wave 8. Baseline values of socio-economic position (mean 1050 (SD 41)) were higher than the national mean of 1000 (SD 100) ${ }^{(61)}$, which suggests less disadvantage and heterogeneity in our sample. Participants' mothers were also slightly more educated than population norms ${ }^{(72)}$. Compared with reference values, adolescent mean BMI $Z$-score was slightly elevated ${ }^{(64)}$, blood pressure was normal ${ }^{(73)}$, and both pulse wave velocity and resting heart rate averages were close to the 25 th percentile ${ }^{(74,75)}$. We are not aware of reference values or cut-off points for children's carotid intima-media thickness and retinal arteriole-to-venule ratio values that have been linked to cardiovascular risk.

Table 3 shows the correlation matrix for study variables. Food diary scores correlated strongly with each other across time but were largely uncorrelated with the measured outcomes. Adolescent blood pressure correlated positively with pulse wave velocity and with resting heart rate (diastolic only).

\section{Dietary trajectories}

Model fit statistics for the two-, three-, four- and fivetrajectory models can be found in Table 4 . Models with two, three and four trajectories had an entropy above $0 \cdot 8$, with the model fit statistics (AIC, BIC, adjusted BIC) decreasing with the addition of extra trajectory classes, indicating improved model fit. The five-trajectory solution led to the identification of two small latent classes ( $\leq 7 \%$ of the sample) but a lower entropy and a larger likelihood ratio $P$ value, so was not appropriate. Therefore, in balancing the a priori model criteria stated above (e.g. entropy above $0 \cdot 8$ ), we selected the four-trajectory model (entropy $=0 \cdot 81$, likelihood ratio test $P=0.09$ ) as it optimised class size, interpretability of trajectories and the model fit statistics. The average posterior probabilities for most likely latent class membership (i.e. the probability that participants were accurately classified into their respective trajectory) were all close to $1 \cdot 0$ : trajectory $1=0 \cdot 98 ;$ trajectory $2=0 \cdot 89 ;$ trajectory $3=0 \cdot 88$; trajectory $4=0 \cdot 89$.

We labelled the four dietary trajectories between age 4 and 15 years as follows.

1. Healthy ( $n$ 40, $21 \%$, mean diet score $=11 \cdot 7$; reference category).

2. Moderately healthy ( $n 87,46 \%$, mean diet score $=10 \cdot 5)$.

3. Moderately unhealthy ( $n 46,25 \%$, mean diet score $=9 \cdot 3$ ).

4. Unhealthy ( $n 15,8 \%$, mean diet score $=7 \cdot 2$ ).

The majority (67\%) of participants followed the two healthiest trajectories. Regardless of dietary trajectory, the 
Table 4 Model fit statistics, PEAS Kids Growth Study, Melbourne, Australia, 2002-2014

\begin{tabular}{lcccccc}
\hline Trajectories & Class sizes $^{*}$ & AIC & BIC & Adjusted BIC $\dagger$ & Entropy & $P$ valueł \\
\hline 2 & $27: 73$ & 4742 & 4823 & 4745 & 0.87 & 0.03 \\
3 & $8: 45: 47$ & 4565 & 4676 & 4568 & 0.84 & 0.07 \\
4 & $\mathbf{8} 24: 46: 22$ & 4507 & 4647 & $\mathbf{4 5 1 1}$ & $\mathbf{0 . 8 1}$ & 0.09 \\
5 & $5: 32: 35: 7: 22$ & 4494 & 4663 & 4499 & 0.79 & 0.30 \\
\hline
\end{tabular}

PEAS, Parent Education and Support; AIC, Akaike's information criterion; BIC, Bayesian information criterion.

Model fit statistics considered included the following: (i) AIC, BIC and adjusted BIC, all of which we aimed to minimise; (ii) model entropy, which we aimed to maximise; and (iii) the $P$ value from the Vuong-Lo-Mendell-Rubin (VLMR) likelihood ratio test of whether adding an additional trajectory category improved model fit. The model chosen is indicated in bold font.

${ }^{*}$ Percentage of the sample in each class/trajectory.

†Adjusted for sample size.

$\ddagger$ VLMR likelihood ratio test $P$ value.

obtained patterns suggest that changes in children's dietary quality occurred during the interval between 6.5 and 10 years of age. Within this period, children in the least healthy trajectories tended to begin an upward trend in diet quality, while those in the healthiest trajectories started to become slightly less healthy. Consequently, all four trajectories converged with age resulting in trajectories that were less distinct by the adolescent years (Fig. 2).

\section{Regression analyses}

No associations were evident between dietary trajectories and blood pressure, pulse wave velocity, carotid intimamedia thickness and retinal arteriole-to-venule ratio. If anything, carotid intima-media thickness was thinner and pulse wave velocity better in those with the least healthy dietary trajectories (Table 5).

In contrast, higher (worse) resting heart rate was associated with worsening dietary trajectories. In the fully adjusted regression model, the effect for the unhealthy trajectory, compared with the reference healthy trajectory, was large and statistically significant (10.5 bpm, 95\% CI

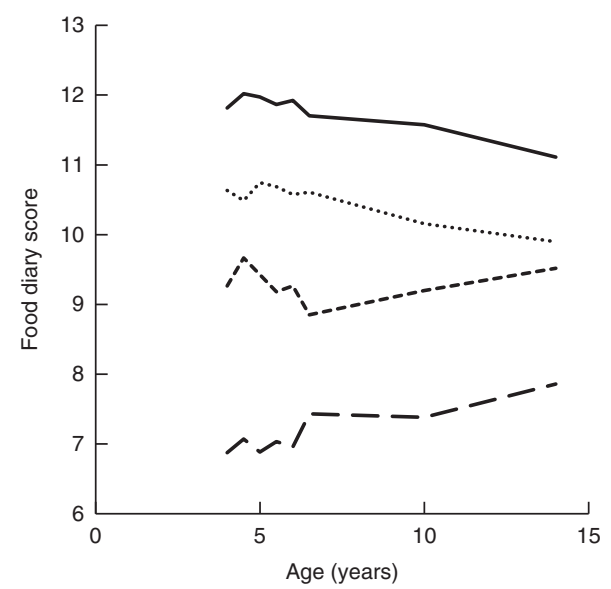

Fig. 2 Empirically derived dietary score trajectories (trajectory 1 : healthy $(21 \%) ; \cdots \ldots .$. , trajectory 2 : moderately healthy $(46 \%)$; --.--., trajectory 3: moderately unhealthy $(25 \%)$; - - , trajectory 4 : unhealthy (8\%)) from age 4 to 15 years among 188 children from the PEAS Kids Growth Study, Melbourne, Australia, 2002-2014 (PEAS, Parent Education and Support)
2.9, 18.0, $d=1 \cdot 1)$. Against available population-based norms (US) for adolescent resting heart rate, this means that children following the least healthy trajectory have a resting heart rate on the 50 th percentile ${ }^{(74)}$, which is more than one standard deviation higher (worse) than those children following the healthiest trajectory, whose resting heart rate is close to the 10th percentile ${ }^{(74)}$. In addition, the effects for the moderately unhealthy $(4.5 \mathrm{bpm}, 95 \% \mathrm{CI}$ $-0.7,9 \cdot 7, d=0.5)$ and moderately healthy ( $4.1 \mathrm{bpm}, 95 \%$ $\mathrm{CI}-0 \cdot 6,8 \cdot 9, d=0 \cdot 4)$ trajectories were in the same direction (Table 5), albeit these effect sizes were small (about onethird of a standard deviation) with higher $P$ values $(P<0 \cdot 10)$. All associations were similar with (shown) and without (not shown) adjustment for concurrent BMI Z-score.

\section{Discussion}

\section{Statement of principal findings}

Of the four dietary trajectories, most participants followed the healthiest trajectories, with only $8 \%$ following the least healthy trajectory. Changes in children's diet quality occurred between 6.5 and 10 years of age, with marked early-life differences in diet quality becoming slightly less marked by adolescence. Finally, independent of potential confounders, children who consumed the least healthy diets recorded the highest resting heart rates, but no differences were evident in other cardiovascular measures.

\section{Comparison with prior literature}

Many Australian children and adolescents fail to meet dietary recommendations ${ }^{(10,11,76)}$, although only $8 \%$ of our sample continually followed the least healthy trajectory. This result is very similar to previous research within population-representative cohorts of Australian children ${ }^{(37)}$, although it is possible that children in our relatively affluent sample follow healthier trajectories than the general population. We also showed that all four typical trajectories inflected to move closer together somewhere between 6.5 and 10 years of age, possibly reflecting the age period at which children gain more influence over their parents' purchasing behaviour and/or when they 


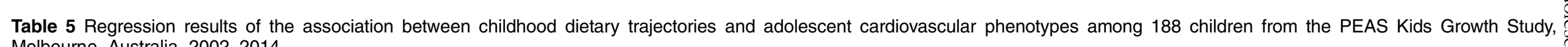
Melbourne, Australia, 2002-2014

\begin{tabular}{|c|c|c|c|c|c|c|c|c|c|c|c|c|c|c|c|c|c|}
\hline \multirow[b]{3}{*}{ Cardiovascular outcome } & \multicolumn{8}{|c|}{ Descriptive statistics } & \multicolumn{9}{|c|}{ Fully adjusted ${ }^{*}$ mean difference from the healthy reference trajectory } \\
\hline & \multicolumn{2}{|c|}{$\begin{array}{l}\text { Healthy trajectory } \\
\text { (reference) }\end{array}$} & \multicolumn{2}{|c|}{$\begin{array}{l}\text { Moderately } \\
\text { healthy } \\
\text { trajectory }\end{array}$} & \multicolumn{2}{|c|}{$\begin{array}{l}\text { Moderately } \\
\text { unhealthy } \\
\text { trajectory }\end{array}$} & \multicolumn{2}{|c|}{$\begin{array}{l}\text { Unhealthy } \\
\text { trajectory }\end{array}$} & \multicolumn{3}{|c|}{$\begin{array}{l}\text { Moderately healthy } \\
\text { trajectory }\end{array}$} & \multicolumn{3}{|c|}{$\begin{array}{l}\text { Moderately unhealthy } \\
\text { trajectory }\end{array}$} & \multicolumn{3}{|c|}{ Unhealthy trajectory } \\
\hline & Mean & SD & Mean & SD & Mean & SD & Mean & SD & $\beta$ & $95 \% \mathrm{Cl}$ & $P$ & $\beta$ & $95 \% \mathrm{Cl}$ & $P$ & $\beta$ & $95 \% \mathrm{Cl}$ & $P$ \\
\hline Resting heart rate $(\mathrm{bpm})$ & & & & & & & & & 4.1 & $-0.6,8.9$ & 0.08 & 4.5 & $-0.7,9.7$ & 0.09 & 10.5 & $2 \cdot 9,18.0$ & 0.01 \\
\hline $\begin{array}{l}\text { Unadjusted } \\
\text { Adiustedt }\end{array}$ & $\begin{array}{l}65 \cdot 1 \\
63.7\end{array}$ & $\begin{array}{r}7.8 \\
12.1\end{array}$ & $\begin{array}{l}67.0 \\
67.9\end{array}$ & $\begin{array}{l}10 \cdot 1 \\
12 \cdot 4\end{array}$ & $67 \cdot 3$ & $\begin{array}{r}9.7 \\
11.5\end{array}$ & $\begin{array}{l}69.7 \\
74.2\end{array}$ & $\begin{array}{l}13 \cdot 5 \\
12.1\end{array}$ & & & & & & & & & \\
\hline $\begin{array}{l}\text { Systolic blood pressure } \\
\text { (mmHg) }\end{array}$ & & & & & & & & & -0.3 & $-4 \cdot 6,4 \cdot 0$ & 0.88 & 1.9 & $-2 \cdot 9,6 \cdot 6$ & 0.43 & $-1 \cdot 1$ & $-8 \cdot 0,5 \cdot 7$ & 0.74 \\
\hline $\begin{array}{l}\text { Unadjusted } \\
\text { Adjusted† }\end{array}$ & $\begin{array}{l}117 \cdot 9 \\
118.8\end{array}$ & $\begin{array}{r}9.5 \\
11.1\end{array}$ & $\begin{array}{l}119 \cdot 2 \\
118 \cdot 4\end{array}$ & $\begin{array}{l}10 \cdot 2 \\
11 \cdot 3\end{array}$ & $\begin{array}{l}120 \cdot 7 \\
120 \cdot 6\end{array}$ & $\begin{array}{r}9.5 \\
10.5\end{array}$ & $\begin{array}{l}119.9 \\
117 \cdot 6\end{array}$ & $\begin{array}{r}7.6 \\
11.0\end{array}$ & & & & & & & & & \\
\hline $\begin{array}{l}\text { Diastolic blood pressure } \\
(\mathrm{mmHg})\end{array}$ & & & & & & & & & 0.3 & $-2 \cdot 7,3 \cdot 2$ & 0.86 & -0.0 & $-3 \cdot 2,3 \cdot 2$ & 0.99 & 0.4 & $-4 \cdot 2,5 \cdot 1$ & 0.85 \\
\hline $\begin{array}{l}\text { Unadjusted } \\
\text { Adjusted } t\end{array}$ & $\begin{array}{l}65 \cdot 1 \\
65.5\end{array}$ & $\begin{array}{l}4.9 \\
7.5\end{array}$ & $\begin{array}{l}66 \cdot 0 \\
65 \cdot 8\end{array}$ & $\begin{array}{l}7 \cdot 1 \\
7.7\end{array}$ & $\begin{array}{l}65 \cdot 8 \\
65.5\end{array}$ & $\begin{array}{l}5.5 \\
7.1\end{array}$ & $\begin{array}{l}67 \cdot 4 \\
66 \cdot 0\end{array}$ & $\begin{array}{l}5 \cdot 6 \\
7.5\end{array}$ & & & & & & & & & \\
\hline $\begin{array}{l}\text { Pulse wave velocity } \\
(\mathrm{m} / \mathrm{s})\end{array}$ & & & 05.0 & & 05.0 & & & & -0.0 & $-0.4,0.4$ & 0.87 & -0.0 & $-0.4,0.3$ & 0.81 & -0.2 & $-0.8,0.3$ & 0.38 \\
\hline Unadjusted & 4.6 & 0.6 & $4 \cdot 7$ & 0.6 & 4.6 & 1.0 & 4.6 & 0.8 & & & & & & & & & \\
\hline Adjusted $\dagger$ & 4.7 & 0.9 & 4.6 & 0.9 & 4.6 & 0.8 & 4.4 & 0.9 & & & & & & & & & \\
\hline $\begin{array}{l}\text { Carotid intima-media } \\
\text { thickness }(\mu \mathrm{m})\end{array}$ & & & & & & & & & $-9 \cdot 4$ & $-45 \cdot 2,26 \cdot 4$ & 0.60 & $-10 \cdot 5$ & $-49 \cdot 7,28 \cdot 7$ & 0.60 & $-14 \cdot 7$ & $-80 \cdot 5,51 \cdot 1$ & 0.66 \\
\hline $\begin{array}{l}\text { Unadjusted } \\
\text { Adjusted } t\end{array}$ & $\begin{array}{l}481.3 \\
483.2\end{array}$ & $\begin{array}{l}54 \cdot 8 \\
67.9\end{array}$ & $\begin{array}{l}472 \cdot 1 \\
473.8\end{array}$ & $\begin{array}{l}62 \cdot 4 \\
70 \cdot 7\end{array}$ & $\begin{array}{l}476 \cdot 1 \\
472 \cdot 7\end{array}$ & $\begin{array}{l}47 \cdot 6 \\
69 \cdot 2\end{array}$ & $\begin{array}{l}470 \cdot 0 \\
468.5\end{array}$ & $\begin{array}{l}81 \cdot 2 \\
71.7\end{array}$ & & & & & & & & & \\
\hline $\begin{array}{l}\text { Retinal arteriole-to-venule } \\
\text { ratio (\%) }\end{array}$ & & & & & & & & & -0.0 & $-2 \cdot 6,2 \cdot 6$ & 0.99 & 1.4 & $-1 \cdot 5,4 \cdot 3$ & 0.33 & $2 \cdot 0$ & $-2 \cdot 9,6 \cdot 9$ & 0.42 \\
\hline Unadjusted & $69 \cdot 5$ & $4 \cdot 0$ & $68 \cdot 8$ & 3.9 & $69 \cdot 6$ & $6 \cdot 6$ & $66 \cdot 7$ & $4 \cdot 3$ & & & & & & & & & \\
\hline Adjusted $†$ & 68.5 & $5 \cdot 1$ & 68.5 & $5 \cdot 3$ & 69.9 & $5 \cdot 2$ & 70.5 & $5 \cdot 4$ & & & & & & & & & \\
\hline
\end{tabular}

PEAS, Parent Education and Support; SEIFA, Socio-Economic Indexes for Areas; IRSD, Index of Relative Socio-economic Disadvantage.

Model statistics remain similar between unadjusted and partially adjusted regression models (i.e. without BMI Z-score). Analytic sample included participants with one or more cardiovascular measure at Wave 8 AND a complete Wave 8 food diary. More stringent food diary inclusion criteria (Wave 1 AND Wave 8 diaries) did not change the trajectories or results obtained.

${ }^{*} A$ priori confounders in adjusted models: Wave 1 maternal education, SEIFA-IRSD score; Wave 8 child age, sex, accelerometer-measured physical activity, adolescent-reported puberty, BMI Z-score.

†Adjusted marginal mean (i.e. the mean adjusted for all a priori confounders in the model). 
begin to have more independent food choice. While we could not pinpoint the timing of these changes more precisely, previous research using the same measure biennially in two large Australian cohorts confirms these inflections and places their timing at about $7-8$ years ${ }^{(37)}$.

The childhood dietary trajectories predicted differences in adolescent resting heart rate. This result aligns with data from the Western Australia Pregnancy (Raine) Cohort ${ }^{(36)}$, where heart rate, but not blood pressure, decreased with better adherence to Australian Dietary Guidelines; thus, a 30 -point change in participants' diet score was associated with a 3-year fall of $2 \cdot 4 \mathrm{bpm}$ between age 14 and 17 years. Although the differences between our study and the Raine study (e.g. age range, dietary measure) preclude direct comparisons, the direction of effect (i.e. healthier diet $=$ lower heart rate) is the same and the magnitude of heart rate change is comparable. We reinforce and extend this finding by demonstrating that following a consistently unhealthy childhood diet is associated with having a resting heart rate that is on average $11 \mathrm{bpm}$ (about one standard deviation) faster in adolescence than the heart rate of children who followed a consistently healthy diet. Moreover, although effect sizes were small and only marginally significant due to our small sample size, the patterns suggest that data follow a dose-response relationship. Thus, children following even moderately healthy diets throughout childhood also recorded a resting heart rate on average $4-5 \mathrm{bpm}$ faster (about one-third of a standard deviation) than did children with consistently healthy diets.

The majority of our results do not support previous research linking childhood or adolescent diet to indicators of cardiovascular health, such as blood pressure or retinal microvascular parameters ${ }^{(18,20,21,24-26,28,29,33)}$. These results were consistently weak, such that this lack of statistical association did not seem to primarily reflect our small sample size. As our study is unique in the frequency and number of dietary measurements, these discrepancies may reflect differences depending on whether diet is measured cumulatively throughout childhood, or whether it is measured infrequently in early life or adolescence. Diet is notoriously difficult to measure via self- and/or parent-report $^{(77)}$ but identifying latent variables across multiple time points should reduce the effect of measurement errors concomitant with the single measures and more reliably identify patterns over time ${ }^{(78)}$.

\section{Strengths and weaknesses}

Because dietary data were questionnaire-based, the trajectories may be subject to reporting bias and these selfreported data did not allow us to account for portion size or the energy density of food items; new online measures with enhanced accuracy should address this issue for future research. Furthermore, we did not have resources to collect data on circulating biomarkers or on cardiorespiratory fitness and our results may therefore be affected by unmeasured residual confounding. In addition, with successive waves, dietary measurement decreased in frequency and graduated from parent- to self-reported. As noted, the diets of children in the healthiest trajectories became less healthy over time, while those in the least healthy trajectories became healthier. While the patterns may resemble regression to the mean, this should not be an issue as latent class analysis considers patterns of diet over the fully observed period without any selectivity of individuals according to extremity of their baseline score. We acknowledge the possibility that these patterns may reflect the change in measurement frequency after Wave 6 and/or child self-reporting diet at Waves 7 and 8, rather than actual dietary change.

The main limitation is the small sample size (especially for the vascular structural measures) and relatively advantaged cohorts available for these exploratory analyses. Clearly, larger studies are needed to confirm and extend these findings, and such data sets are now becoming available. Nevertheless, the current study is strengthened by its longitudinal design, community sample, repeated dietary measures throughout the early life course, and the unusual rigour and breadth of cardiovascular measures that have been out of reach of most previous studies. Our adjustment for multiple confounding variables may partly explain differences in effect sizes with previous research.

\section{Implications}

The differences between 'typical' dietary pathways followed by Australian children in our small study were striking. Very marked differentiation of long-term diet quality trajectories was entrenched by the pre-school years, suggesting that interventions to maximise dietary healthfulness may need to occur in the early years. Given the continuity of autonomic risk across the full range of dietary quality, such interventions may need to be universal. Conversely, interventions in the early primary school years may best be specifically designed to ward off declines in dietary quality - needing different strategies. Nevertheless, because effects did not emerge for the remaining cardiovascular measures, we recommend replication of our data before drawing this conclusion.

Heart rate (a reflection of sympathetic nervous system activity) and vascular function are correlated; for example, a reduction in vascular stiffness following weight loss in obese 20-45-year-old adults paralleled concomitant slowing of resting heart rate ${ }^{(79)}$. There is good evidence that risk factors present early in the life course increase the risk of CVD in adulthood ${ }^{(8)}$. Supported by previous research during later adolescence ${ }^{(36)}$, our study raises the novel possibility that dietary trajectories in healthy children may effect changes in heart rate by age 15 years, with diet-related changes in adult arterial stiffness potentially following ${ }^{(80)}$. What little evidence exists for adolescents is inconsistent as to the importance of heart rate differences 
within the normal range ${ }^{(55,81)}$. However, small increments in adult resting heart rate (often within the normal range) predict both cardiovascular and all-cause mortality over a relatively short period ${ }^{(54,82)}$. In the Atherosclerosis Risk in Communities (ARIC) study of middle-aged adults, every 5bpm increase in resting heart rate from the preceding visit ( $\approx 3$ years previously) incurred $\mathrm{a} \approx 12 \%$ increased risk of mortality over 28 years of follow-up ${ }^{(82)}$. Additional analyses demonstrated that this risk was associated with a time-adjusted resting heart rate of $>66 \mathrm{bpm}$, compared with $60 \mathrm{bpm}$. This suggests that the size of our apparent dose-response differences in adolescent resting heart rate by worsening childhood diet quality trajectories is important, with our adjusted means higher among each worsening diet trajectory (63.7 to 67.9 to 68.2 to $74.2 \mathrm{bpm}$; Table 5). The ARIC findings ${ }^{(82)}$ suggest that these effects sizes could be very important to later-life mortality if relationships between diet quality and resting heart rate remain stable or become more pronounced with age. Future research should examine whether improving diet before or during the adolescent years lowers heart rate and mitigates adult cardiovascular risk.

\section{Conclusion}

Our study extends currently limited research investigating childhood diet and early-life cardiovascular phenotypes. Decade-long dietary trajectories in healthy children did not appear to influence macro- or microvascular structure or stiffness by mid-adolescence, but were associated with resting heart rate, suggesting an early-life window for prevention. Although participants' heart rate values were within the normal range, the obtained gradient in adolescence may have cumulative long-term impacts on lifecourse outcomes. Larger studies are needed to confirm these findings, the threshold of diet quality associated with these physiological changes and whether functional changes in heart rate are followed by structural changes in large and small vessel phenotypes.

\section{Acknowledgements}

Acknowledgements: The authors thank all the research staff, Maternal and Child Health Nurses and families involved in the PEAS Programme and PEAS Kids Growth Study. They thank Greta Goldsmith for analysing the carotid intima-media thickness images and the Centre for Eye Research Australia for analysing the retinal photography images. Financial support: Early waves of the PEAS Kids Growth Study were funded by the Australian National Health and Medical Research Council (NHMRC Project Grant numbers 284509 and 284582) and the Murdoch Children's Research Institute. The 2014 wave of the PEAS study received internal funding from the Murdoch Chil- dren's Research Institute Population Health Theme and the Centre for Community Child Health. M.W. was supported by an NHMRC Senior Research Fellowship (grant number 1046518) and Cure Kids New Zealand, F.K.M. by an NHMRC Career Development Fellowship (grant number 1111160), A.N.G. by an Australian Postgraduate Award and C.E.G. by an Australian Government Research Training Program Scholarship. D.B. was supported by an NHMRC Senior Research Fellowship (grant number 1064629) and is an Honorary Future Leader Fellow of the National Heart Foundation of Australia. Research at the Murdoch Children's Research Institute is supported by the Victorian Government's Operational Infrastructure Support Programme. The researchers were independent of the funders and do not have any relevant financial interests in the manuscript. The funding organisations had no role in the design, analysis or writing of this article. Conflicts of interest: The authors have no potential conflicts to disclose. Authorship: M.W. led the PEAS Kids Growth Study and the PEAS follow-up. Follow-up data collection was completed by J.A.K. and A.N.G. This study question was conceived by J.A.K. J.A.K., A.N.G. and C.E.G. conducted the statistical analysis, in consultation with F.K.M. J.A.K. wrote the first draft of this manuscript, which was revised by A.N.G., C.E.G., D.B., F.K.M. and M.W. All authors have seen and approved the final version. Ethics of buman subject participation: This study was conducted according to the guidelines laid down in the Declaration of Helsinki and all procedures involving human subjects were approved by The Melbourne Royal Children's Hospital Ethics Committee (approval number 28153). Written informed consent was obtained from all subjects or their parent.

\section{References}

1. Groner JA, Joshi M \& Bauer JA (2006) Pediatric precursors of adult cardiovascular disease: noninvasive assessment of early vascular changes in children and adolescents. Pediatrics 118, 1683-1691.

2. Mendis S (2014) Global Status Report on NonCommunicable Diseases. Geneva: WHO.

3. Giugliano D, Ceriello A \& Esposito K (2006) The effects of diet on inflammation: emphasis on the metabolic syndrome. J Am Coll Cardiol 48, 677-685.

4. Kant AK (2004) Dietary patterns and health outcomes. J Am Diet Assoc 104, 615-635.

5. Engelfriet P, Hoekstra J, Hoogenveen R et al. (2010) Food and vessels: the importance of a healthy diet to prevent cardiovascular disease. Eur J Cardiovasc Prev Rehabil 17, 50-55.

6. Siervo M, Lara J, Chowdhury S et al. (2015) Effects of the Dietary Approach to Stop Hypertension (DASH) diet on cardiovascular risk factors: a systematic review and metaanalysis. Br J Nutr 113, 1-15.

7. Kaikkonen JE, Mikkilä V, Magnussen CG et al. (2013) Does childhood nutrition influence adult cardiovascular disease risk? - insights from the Young Finns Study. Ann Med 45, 120-128.

8. Magnussen CG, Smith KJ \& Juonala M (2014) What the long term cohort studies that began in childhood have taught us about the origins of coronary heart disease. Curr Cardiovasc Risk Rep 8, 373. 
9. Kaikkonen JE, Mikkilä V \& Raitakari OT (2014) Role of childhood food patterns on adult cardiovascular disease risk. Curr Atheroscler Rep 16, 443.

10. Rangan A, Randall D, Hector D et al. (2008) Consumption of 'extra' foods by Australian children: types, quantities and contribution to energy and nutrient intakes. Eur J Clin Nutr 62, 356-364.

11. Scully M, Morley B, Niven P et al. (2012) Overweight/obesity, physical activity and diet among Australian secondary students - first national dataset 2009-10. Cancer Forum 36, 19.

12. Simell O, Niinikoski H, Rönnemaa T et al. (2009) Cohort profile: the STRIP study (Special Turku Coronary Risk Factor Intervention Project), an infancy-onset dietary and life-style intervention trial. Int J Epidemiol 38, 650-655.

13. Pahkala K, Hietalampi H, Laitinen TT et al. (2013) Ideal cardiovascular health in adolescence: effect of lifestyle intervention and association with vascular intima-media thickness and elasticity (The STRIP Study). Circulation 127, 2088-2096.

14. Niinikoski H, Lagström H, Jokinen E et al. (2007) Impact of repeated dietary counseling between infancy and 14 years of age on dietary intakes and serum lipids and lipoproteins. Circulation 116, 1032-1040.

15. Niinikoski H, Pahkala K, Ala-Korpela M et al. (2012) Effect of repeated dietary counseling on serum lipoproteins from infancy to adulthood. Pediatrics 129, e704-e713.

16. Niinikoski H, Jula A, Viikari J et al. (2009) Blood pressure is lower in children and adolescents with a low-saturated-fat diet since infancy. Hypertension 53, 918-924.

17. Funtikova AN, Navarro E, Bawaked RA et al. (2015) Impact of diet on cardiometabolic health in children and adolescents. Nutr J 14, 118.

18. Payab M, Kelishadi R, Qorbani M et al. (2015) Association of junk food consumption with high blood pressure and obesity in Iranian children and adolescents: the CaspianIV Study. J Pediatr (Rio J) 91, 196-205.

19. Bel-Serrat S, Mouratidou T, Börnhorst C et al. (2013) Food consumption and cardiovascular risk factors in European children: the IDEFICS study. Pediatr Obes 8, 225-236.

20. Kell KP, Cardel MI, Brown MMB et al. (2014) Added sugars in the diet are positively associated with diastolic blood pressure and triglycerides in children. Am J Clin Nutr 100, 46-52.

21. Jenner D, English D, Vandongen R et al. (1988) Diet and blood pressure in 9-year-old Australian children. Am J Clin Nutr 47, 1052-1059.

22. Nicklas TA, Dwyer J, Feldman HA et al. (2002) Serum cholesterol levels in children are associated with dietary fat and fatty acid intake. J Am Diet Assoc 102, 511-517.

23. Shea S, Basch CE, Irigoyen $M$ et al. (1991) Relationships of dietary fat consumption to serum total and low-density lipoprotein cholesterol in Hispanic preschool children. Prev Med 20, 237-249.

24. da SN, Souza B, Cunha DB, Pereira RA et al. (2016) Soft drink consumption, mainly diet ones, is associated with increased blood pressure in adolescents. J Hypertens $\mathbf{3 4}$, 221-225.

25. Ulbak J, Lauritzen L, Hansen HS et al. (2004) Diet and blood pressure in 2.5-y-old Danish children. Am J Clin Nutr 79 , 1095-1102.

26. Gopinath B, Flood VM, Wang JJ et al. (2012) Carbohydrate nutrition is associated with changes in the retinal vascular structure and branching pattern in children. Am J Clin Nutr 95, 1215-1222.

27. Ambrosini GL, Oddy WH, Huang RC et al. (2013) Prospective associations between sugar-sweetened beverage intakes and cardiometabolic risk factors in adolescents. $A m J$ Clin Nutr 98, 327-334.

28. Gopinath B, Flood VM, Burlutsky G et al. (2014) Dairy food consumption, blood pressure and retinal microcirculation in adolescents. Nutr Metab Cardiovasc Dis 24, 1221-1227.
29. Moore LL, Bradlee ML, Singer MR et al. (2012) Dietary Approaches to Stop Hypertension (DASH) eating pattern and risk of elevated blood pressure in adolescent girls. $\mathrm{Br} \mathrm{J}$ Nutr 108, 1678-1685.

30. Geogousopoulou EN, Panagiotakos DB, Pitsavos C et al. (2014) Assessment of diet quality improves the classification ability of cardiovascular risk score in predicting future events: the 10-year follow-up of the ATTICA study (20022012). Eur J Prev Cardiol 22, 1488-1498.

31. Arvaniti F \& Panagiotakos DB (2008) Healthy indexes in public health practice and research: a review. Crit Rev Food Sci Nutr 48, 317-327.

32. Lazarou C \& Newby P (2011) Use of dietary indexes among children in developed countries. Adv Nutr 2, 295-303.

33. Lazarou C, Panagiotakos DB \& Matalas A-L (2009) Foods E-KINDEX: a dietary index associated with reduced blood pressure levels among young children: the CYKIDS study. J Am Diet Assoc 109, 1070-1075.

34. Lydakis C, Stefanaki E, Stefanaki S et al. (2012) Correlation of blood pressure, obesity, and adherence to the Mediterranean diet with indices of arterial stiffness in children. Eur J Pediatr 171, 1373-1382.

35. Cuenca-García M, Ortega F, Ruiz J et al. (2014) Combined influence of healthy diet and active lifestyle on cardiovascular disease risk factors in adolescents. Scand J Med Sci Sports 24, 553-562.

36. Ping-Delfos WLCS, Beilin LJ, Oddy WH et al. (2015) Use of the dietary guideline index to assess cardiometabolic risk in adolescents. Br J Nutr 113, 1741-1752.

37. Gasser C, Kerr JA, Mensah FK et al. (2017) Stability and change in dietary scores and patterns across six waves of the Longitudinal Study of Australian Children. BrJ Nutr 117, $1137-1150$.

38. Batis C, Mendez MA, Sotres-Alvarez D et al. (2014) Dietary pattern trajectories during 15 years of follow-up and HbA1c, insulin resistance and diabetes prevalence among Chinese adults. J Epidemiol Community Health 68, 773-779.

39. Mikkilä V, Räsänen L, Raitakari $\mathrm{O}$ et al. (2005) Consistent dietary patterns identified from childhood to adulthood: the Cardiovascular Risk in Young Finns Study. Br J Nutr 93, 923-931.

40. Brazionis L, Golley RK, Mittinty MN et al. (2012) Characterization of transition diets spanning infancy and toddlerhood: a novel, multiple-time-point application of principal components analysis. Am J Clin Nutr 95, 1200-1208.

41. Lioret S, Betoko A, Forhan A et al. (2015) Dietary patterns track from infancy to preschool age: cross-sectional and longitudinal perspectives. J Nutr 145, 775-782.

42. Boddy L, Abayomi J, Johnson B et al. (2014) Ten-year changes in positive and negative marker food, fruit, vegetables, and salad intake in 9-10 year olds: SportsLinx 20002001 to 2010-2011. J Hum Nutr Diet 27, 236-241.

43. Rauber F, Hoffman DJ \& Vitolo MR (2014) Diet quality from pre-school to school age in Brazilian children: a 4-year follow-up in a randomised control study. Br J Nutr 111, 499-505.

44. Barnes TL, Crandell JL, Bell RA et al. (2013) Change in DASH diet score and cardiovascular risk factors in youth with type 1 and type 2 diabetes mellitus: the SEARCH for Diabetes in Youth Study. Nutr Diabetes 3, e91.

45. Meyerkort C, Oddy WH, O'Sullivan T et al. (2012) Early diet quality in a longitudinal study of Australian children: associations with nutrition and body mass index later in childhood and adolescence. J Dev Orig Health Dis 3, 21-31.

46. Lioret S, McNaughton SA, Cameron AJ et al. (2014) Threeyear change in diet quality and associated changes in BMI among schoolchildren living in socio-economically disadvantaged neighbourhoods. Br J Nutr 112, 260-268.

47. McCourt HJ, Draffin CR, Woodside JV et al. (2014) Dietary patterns and cardiovascular risk factors in adolescents and 
young adults: the Northern Ireland Young Hearts Project. Br J Nutr 112, 1685-1698.

48. Hollar DW (2017) Trajectory Analysis in Health Care. Cham: Springer.

49. Hanvey AN, Clifford SA, Mensah FK et al. (2016) Which body composition measures are associated with cardiovascular function and structure in adolescence? Obes Med $\mathbf{3}$ 20-27.

50. Wake M, Morton-Allen E, Poulakis Z et al. (2006) Prevalence, stability, and outcomes of cry-fuss and sleep problems in the first 2 years of life: prospective community-based study. Pediatrics 117, 836-842.

51. Hanvey AN, Mensah FK, Clifford SA et al. (2017) Adolescent cardiovascular functional and structural outcomes of growth trajectories from infancy: prospective community-based study. Child Obes 13, 154-163.

52. Hanson KL \& Olson CM (2013) School meals participation and weekday dietary quality were associated after controlling for weekend eating among US school children aged 6 to 17 years. J Nutr 143, 714-721.

53. National Health and Medical Research Council (2013) Australian Dietary Guidelines. Canberra: NHMRC.

54. Zhang D, Shen X \& Qi X (2016) Resting heart rate and allcause and cardiovascular mortality in the general population: a meta-analysis. CMAJ 188, E53-E63.

55. Farah BQ, Christofaro DGD, Balagopal PB et al. (2015) Association between resting heart rate and cardiovascular risk factors in adolescents. Eur J Pediatr 174, 1621-1628.

56. Franklin SS \& Wong ND (2013) Hypertension and cardiovascular disease: contributions of the Framingham Heart Study. Glob Heart 8, 49-57.

57. Laurent S, Cockcroft J, Van Bortel L et al. (2006) Expert consensus document on arterial stiffness: methodological issues and clinical applications. Eur Heart J 27, 2588-2605.

58. Nürnberger J, Keflioglu-Scheiber A, Saez AMO et al. (2002) Augmentation index is associated with cardiovascular risk. J Hypertens 20, 2407-2414.

59. Hwang M, Yoo J, Kim H et al. (2014) Validity and reliability of aortic pulse wave velocity and augmentation index determined by the new cuff-based SphygmoCor Xcel. J Hum Hypertens 28, 475-481.

60. Hubbard LD, Brothers RJ, King WN et al. (1999) Methods for evaluation of retinal microvascular abnormalities associated with hypertension/sclerosis in the Atherosclerosis Risk in Communities Study. Ophthalmology 106, 2269-2280.

61. Adhikari P (2006) Socio-Economic Indexes for Areas: Introduction, Use and Future Directions. Canberra: Australian Bureau of Statistics.

62. Petersen AC, Crockett L, Richards M et al. (1988) A selfreport measure of pubertal status: reliability, validity, and initial norms. J Youth Adolesc 17, 117-133.

63. Evenson KR, Catellier DJ, Gill K et al. (2008) Calibration of two objective measures of physical activity for children. J Sports Sci 26, 1557-1565.

64. Kuczmarski RJ, Ogden CL, Guo SS et al. (2002) 2000 CDC growth charts for the United States: methods and development. Vital Health Stat 11 issue 246, 1-190.

65. Vidmar SI, Cole TJ \& Pan H (2013) Standardizing anthropometric measures in children and adolescents with functions for egen: update. Stata J 13, 366-378.
66. Muthen L (2007) Mplus User's Guide, 5th ed. Los Angeles, CA: Muthen \& Muthen.

67. Nylund KL, Asparouhov T \& Muthén BO (2007) Deciding on the number of classes in latent class analysis and growth mixture modeling: a Monte Carlo simulation study. Struct Equ Modeling 14, 535-569.

68. Jung T \& Wickrama KAS (2008) An introduction to latent class growth analysis and growth mixture modeling. SOC Pers Psychol Compass 2, 302-317.

69. Reinehr T \& Toschke AM (2009) Onset of puberty and cardiovascular risk factors in untreated obese children and adolescents: a 1-year follow-up study. Arch Pediatr Adolesc Med 163, 709-715.

70. Cutler GJ, Flood A, Hannan P et al. (2011) Multiple sociodemographic and socioenvironmental characteristics are correlated with major patterns of dietary intake in adolescents. J Am Diet Assoc 111, 230-240.

71. Cheng G, Gerlach S, Libuda L et al. (2010) Diet quality in childhood is prospectively associated with the timing of puberty but not with body composition at puberty onset. J Nutr 140, 95-102.

72. Australian Bureau of Statistics (2015) Qualifications and Work, Australia, 2015. http://www.abs.gov.au/ausstats/ abs@.nsf/0/1839355F55AC72F6CA2579AA000F256C?Open document (accessed March 2017).

73. Falkner B, Daniels SR, Flynn JT et al. (2004) The fourth report on the diagnosis, evaluation, and treatment of high blood pressure in children and adolescents. Pediatrics $\mathbf{1 1 4}$ 555-576.

74. Ostchega Y, Porter KS, Hughes J et al. (2011) Resting pulse rate reference data for children, adolescents, and adults: United States, 1999-2008. Natl Health Stat Report issue 41, 1-16.

75. Reusz GS, Cseprekal O, Temmar M et al. (2010) Reference values of pulse wave velocity in healthy children and teenagers. Hypertension 56, 217-224.

76. Whitrow MJ, Moran L, Davies MJ et al. (2016) Core food intakes of Australian children aged 9-10 years: nutrients, daily servings and diet quality in a community crosssectional sample. J Hum Nutr Diet 29, 449-457.

77. Archer E \& Blair SN (2015) Implausible data, false memories, and the status quo in dietary assessment. Adv Nutr $\mathbf{6}$, $229-230$

78. Kaldor J \& Clayton D (1985) Latent class analysis in chronic disease epidemiology. Stat Med 4, 327-335.

79. Cooper JN, Buchanich JM, Youk A et al. (2012) Reductions in arterial stiffness with weight loss in overweight and obese young adults: potential mechanisms. Atherosclerosis 223, 485-490.

80. Aatola H, Koivistoinen T, Hutri-Kähönen N et al. (2010) Lifetime fruit and vegetable consumption and arterial pulse wave velocity in adulthood the cardiovascular risk in Young Finns Study. Circulation 122, 2521-2528.

81. de Moraes ACF, Cassenote AJF, Leclercq C et al. (2015) Resting heart rate is not a good predictor of a clustered cardiovascular risk score in adolescents: the HELENA Study. PLoS One 10, e0127530.

82. Vazir A, Claggett B, Cheng S et al. (2018) Association of resting heart rate and temporal changes in heart rate with outcomes in participants of the Atherosclerosis Risk in Communities Study. JAMA Cardiol 3, 200-206. 